\title{
Pulmonary Artery Aneurysm Repair with Alpha-1 Anti-trypsin Deficiency
}

\author{
Brett Starr ${ }^{1}$, Caitlin Takahashi-Pipkin ${ }^{1}$, Michael Bates $^{1}$, and Shahab Akhter ${ }^{1}$ \\ ${ }^{1}$ East Carolina Heart Institute
}

September 25, 2021

\begin{abstract}
A 62-year-old woman with pulmonary hypertension due to alpha-1 antitrypsin deficiency and known congenital pulmonic valve stenosis presented with palpitations, chest pressure and bradycardia and was found to have a 6 cm pulmonary artery aneurysm on work-up. The patient underwent surgical pulmonary artery aneurysm repair and recovered from operation without complications.
\end{abstract}

\section{Introduction}

Pulmonary artery aneurysm may be associated with congenital cardiac anomalies over $50 \%$ of the time, including pulmonary artery stenosis. ${ }^{1}$ There are few reports of isolated congenital pulmonic valve stenosis with associated pulmonary artery aneurysm, and no reports of open repair in a patient with Alpha-1 Antitrypsin deficiency. ${ }^{2}{ }^{3}$ We present a case of a patient with Alpha-1 Antitrypsin deficiency who presented with idiopathic congenital pulmonic valve stenosis, with findings of a pulmonary artery aneurysm, and successful open operative repair.

\section{Case Report}

A 62-year-old female with history of Alpha-1 Antitrypsin deficiency and congenital pulmonic valve (PV) stenosis presented with symptoms of palpitations, lightheadedness, chest pressure, and bradycardia. A comprehensive cardiac evaluation was performed including cardiac catheterization which did not demonstrate coronary disease, however, was concerning for PV stenosis. Follow-up MRI demonstrated mild PV stenosis, but incidentally noted a significant post-stenotic pulmonary artery (PA) aneurysm measuring $6 \mathrm{~cm}$ with extension into the left PA. [Figure 1] She continued to have symptoms of palpitations and chest pressure. Given the size of the aneurysm, she was offered surgical repair due to the increased risk of PA rupture, similar to guidelines for aortic aneurysms.

She was taken to the operating room and underwent a median sternotomy, was placed on cardiopulmonary bypass, and the heart was arrested. The aortopulmonary groove was dissected free and the main PA was encircled. Dissection was carried down the left PA until it exited the pericardium, where the size was dilated, but had tapered to within a normal range. The PA bifurcation was isolated and dissected free, and the right PA was dissected free under the aorta and to the exit of the pericardium. The right PA was of normal size distally. With full exposure, the PA was transected about $1.0 \mathrm{~cm}$ distal to the PV and carried up toward the left PA. The bifurcation was preserved as a potential reimplantation button. The left PA was transected distally leaving only a small sewing cuff along the pericardium. A $26 \mathrm{~mm}$ Gelweave graft was used to reconstruct the main to left PA segment as an interposition graft. The right PA was felt to be dilated at the bifurcation and an $18 \mathrm{~mm}$ Gelweave graft was used to reconstruct the right PA segment underlying the aorta as an interposition graft to main Gelweave graft. [Figure 2] TEE at the conclusion of 
the operation demonstrated no significant PV stenosis and good luminal flow through both PA branches of the reconstruction.

The patient tolerated the procedure without any difficulties and was discharged on POD 4 after an unremarkable course. She was doing well at 2- and 4-week follow-up and completed cardiopulmonary rehabilitation. She has continued to have aggressive pulmonary management due to her Alpha-1 Antitrypsin deficiency but has recovered completely from her surgical intervention.

\section{Comment}

Pulmonary artery aneurysms are found in approximately 1 in 14,000 autopsies, with most being asymptomatic, but some causing symptoms that can develop life-threatening complications. ${ }^{4}$ Many times, patients with pulmonary artery aneurysms have other cardiac or large vessel anomalies, but there are few cases reported on isolated pulmonary valve disease in association with pulmonary artery aneurysms. ${ }^{4,5}$ Our patient is unique due to her Alpha-1 Antitrypsin Deficiency. She successfully underwent replacement of her pulmonary artery aneurysm with an interposition graft without complications.

\section{Figure Legends}

Figure 1. Cardiac MRI demonstrating pulmonary artery aneurysm.

Figure 2. Intra-operative image after interposition graft was completed.

\section{References}

1. Kreibich M, Siepe M, Kroll J, Höhn R, Grohmann J, Beyersdorf F. Aneurysms of the pulmonary artery. Circulation. Jan 2015;131(3):310-6. doi:10.1161/CIRCULATIONAHA.114.012907

2. Izumida S, Kawano H, Tsuneto A, Doi Y, Maemura K. Pulmonary Artery Aneurysm Associated with Bicuspid Pulmonary Valve. Intern Med . Aug 2020;59(15):1867-1871. doi:10.2169/internalmedicine.4415-20

3. Maldonado J, Cabrera F, Nieves M, Torres-Ayala S, Otero P. WHAT LURKS BENEATH: INCIDENTAL FINDING OF A PULMONARY ARTERY ANEURYSM SECONDARY TO PULMONARY VALVE STENOSIS. Journal of the American College of Cardiology: Elsevier; 2019.

4. Gupta M, Agrawal A, Iakovou A, Cohen S, Shah R, Talwar A. Pulmonary artery aneurysm: a review. Pulm Circ . 2020 Jan-Mar 2020;10(1):2045894020908780. doi:10.1177/2045894020908780

5. Duijnhouwer AL, Navarese EP, Van Dijk AP, Loeys B, Roos-Hesselink JW, De Boer MJ. Aneurysm of the Pulmonary Artery, a Systematic Review and Critical Analysis of Current Literature. Congenit Heart Dis . 2016 Mar-Apr 2016;11(2):102-9. doi:10.1111/chd.12316 


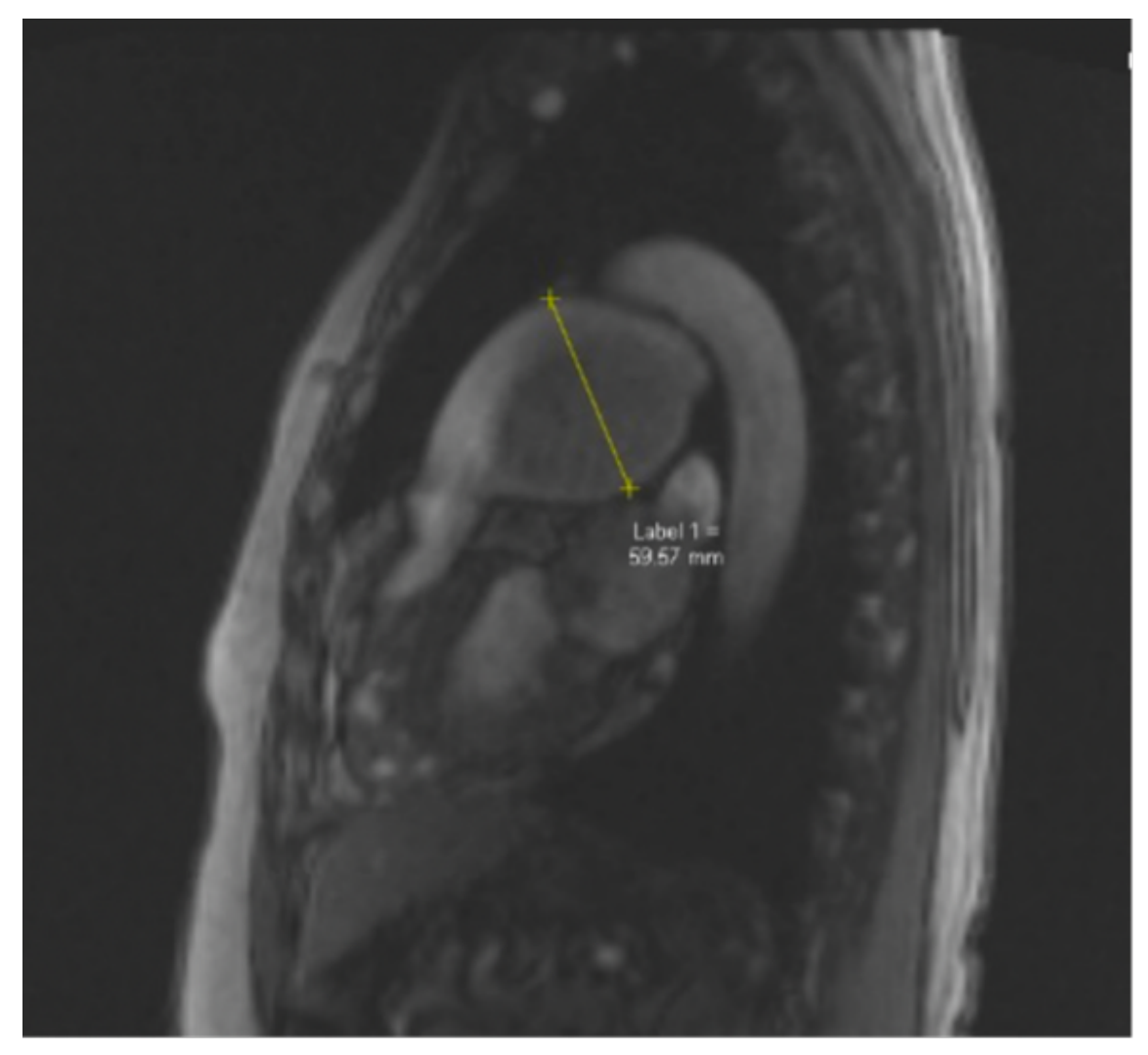




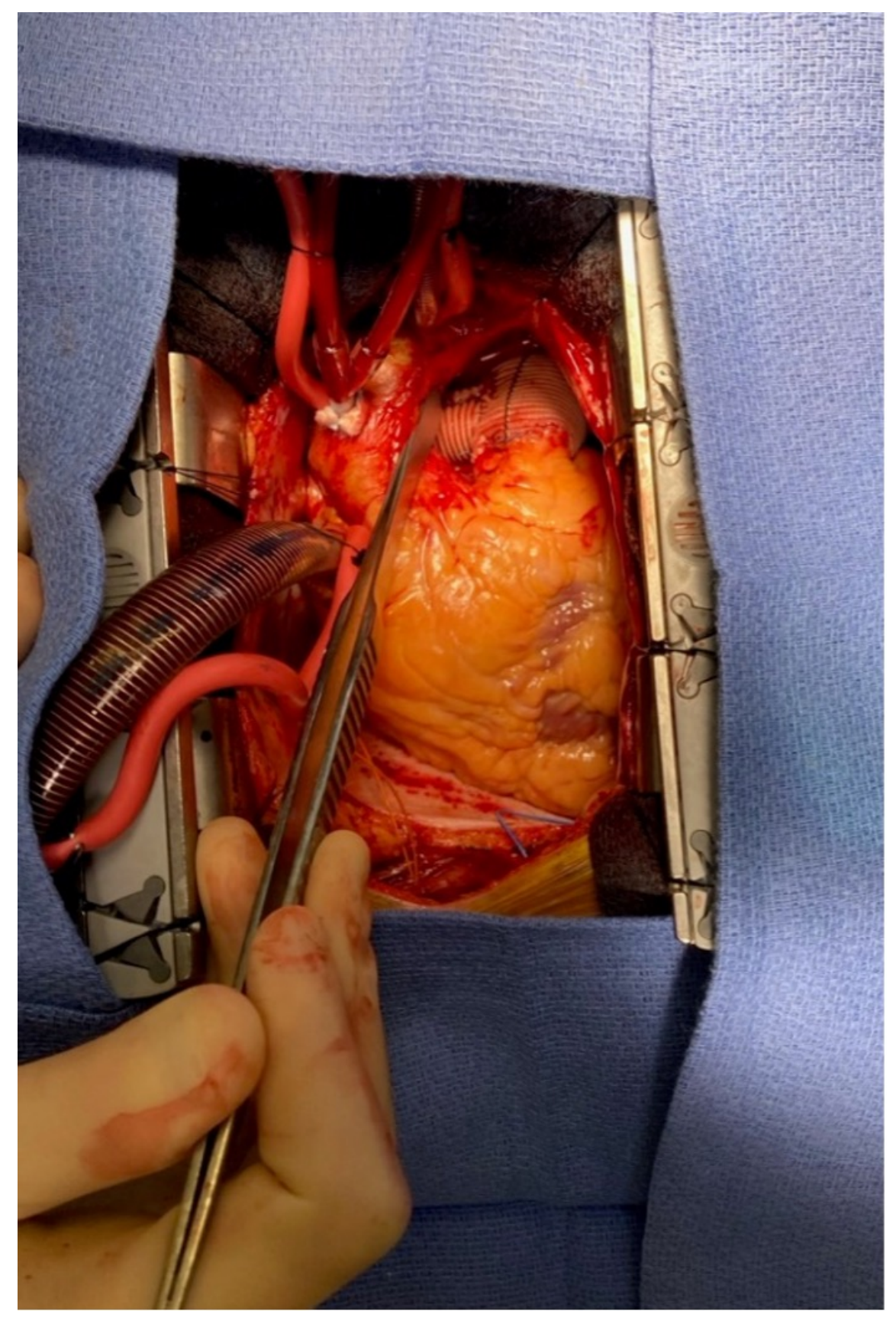

